\title{
As vivências maternas diante do abuso sexual intrafamiliar
}

\author{
Joana Azevêdo Lima \\ Maria de Fatima Pereira Alberto \\ Universidade Federal da Paraiba
}

\begin{abstract}
Resumo
A violência sexual intrafamiliar contra crianças e adolescentes assume na contemporaneidade contornos de problema de ordem pública. Este artigo tem como objetivo analisar as vivências subjetivas das mães que tiveram suas filhas abusadas sexualmente dentro do contexto familiar. Participaram da pesquisa 13 mães, entre 25 e 50 anos, atendidas no Programa Sentinela, selecionadas por conveniência, com amostra determinada por critério de saturação, submetidas à entrevista semiestruturada, com questões versando sobre dados biossociodemográficos e história de vida e submetidas à técnica de análise de conteúdo temático. As vivências subjetivas diante da situação revelada são experimentadas a partir de sentimentos negativos como culpa, desconfiança, desamparo e embotamento afetivo, associam ainda à sua experiência, quando foram também vitimadas na infância. As mães tornam-se alvos de carga emocional negativa, que leva ao sofrimento subjetivo, o que norteia a forma com que se posicionam e procedem diante do conhecimento do abuso.
\end{abstract}

Palavras-chave: Abuso sexual; mães; vivências subjetivas.

\begin{abstract}
The maternal experiences front of the intrafamily sexual abuse. Intrafamily sexual violence against children and adolescents in contemporary takes on the contours of public order problem. This article aims to analyze the subjective experiences of mothers who had sexually abused their daughters within the family context. 13 mothers, with age between 25 and 50 years old, participated in the survey. They were attended the Sentinel Program and selected by convenience sample measured with the criterion of saturation. Woman were submitted to a semi-structured questions dealing with bio-data on socio-demographic and life history technique and subjected to thematic content analysis. The subjective experiences with the situation revealed are experienced based on negative feelings such as guilt, distrust, helplessness and blunting of affect, even to associate your experience, when they were also victimized in childhood. Mothers become targets of negative emotions, which leads to subjective distress, which guides the way they position themselves and proceed with the knowledge of the abuse.
\end{abstract}

Keywords: Sexual abuse; mothers; subjective experiences.

$\mathrm{O}$ abuso sexual intrafamiliar infanto-juvenill é uma realidade presente no Brasil e no mundo. Segundo dados do serviço do Disque-Denúncia Nacional, registrados do ano de 2003 até novembro de 2007, houve cerca de 28.480 denúncias referentes a abuso sexual, exploração sexual, violência, tráfico e negligência envolvendo crianças e adolescentes, dos quais, 7.824 relativos a abuso sexual infantojuvenil, superado apenas por registros de negligência e violência em geral (Centro de Referência, Estudos e Ações sobre Crianças e Adolescentes [CECRIA], s/d).

Diante de dados controversos, dada a subnotificação no Brasil, vários autores têm se debruçado sobre o tema abuso sexual contra crianças e adolescentes e o estudado sob vários aspectos, de que se destacam: trajetória histórica (Aded, Dalcin, Moraes, \& Cavalcanti, 2006; Ariès, 1981; Azevedo \& Guerra, 1993), problema de saúde pública (Faleiros, 2000; Habigzang, Koller, Azevedo, \& Machado, 2005), dados epidemiológicos (Azambuja, 2004; Cohen, 1993; Forward \& Buck, 1989), conceituação e tipologia (Azambuja, 2004; Forward \& Buck, 1989; Pfeiffer \& Salvagni, 2005; Secretaria Especial dos Direitos Humanos \& Ministério da Educação, 2004), consequências (Forward \& Buck, 1989; Furniss, 1993), causas (Amazarrey \& Koller, 1998; Antoni \& Koller, 2000; Araújo, 2002; Avancini, 2004; Furniss, 1993; Gabel, 1991; Habigzang \& Caminha, 2004; 
Libório, 2005; Libório \& Souza, 2004; Mees, 2001; Narvaz, 2005; Pfeiffer \& Salvagni, 2005; Renshaw, 1984), família (Azambuja, 2004; Forward \& Buck, 1989; Furniss, 1993) sobre as mães (Freitas, 2002; Furniss, 1993; Narvaz, 2005).

O abuso sexual caracteriza-se por uma assimetria determinante para a condição de abuso de uma pessoa sobre outra. Trata-se da concepção de que o agressor possui desenvolvimento psíquico ou físico maior que o de sua vitimada, o que torna comum a presença de outros artifícios de manifestação desse domínio, como ameaça ou chantagem (Azambuja, 2004; Forward \& Buck, 1989; Furniss, 1993; Habigzang \& Caminha, 2004).

Tal violência pode ocorrer tanto em âmbito extrafamiliar (agressor não possui vínculo familiar com a vitimada), como intrafamiliar. Segundo definição de Forward e Buck (1989), no abuso sexual intrafamiliar ocorre uma relação incestuosa, que envolve relação sexual entre pessoas com um grau próximo de parentesco ou por afinidade entre elas. Essa definição ultrapassa a discussão legal e reducionista de grau de parentesco para transitar pela construção do significado que o agressor tem na concepção da sua vitimada.

Trata-se de uma modalidade de violência diretamente relacionada ao gênero. Os dados encontrados na literatura existente revelam que o feminino é o mais vitimado, e que as possíveis causas residem nas dimensões androcêntricas e nos aspectos sócio-históricos que nutrem as mais antigas formações sociais (Amazarrey \& Koller, 1998; Antoni \& Koller, 2000; Araújo, 2002; Avancini, 2004; Furniss, 1993; Gabel, 1991; Habigzang \& Caminha, 2004; Habigzang et al., 2005; Libório, 2005; Libório \& Souza, 2004; Mees, 2001; Narvaz, 2005; Pfeiffer \& Salvagni, 2005; Renshaw, 1984).

Para efeito desta pesquisa, utilizou-se a definição desenvolvida por Azevedo e Guerra (1989) acerca das expressões vitimados e vitimizados, ao referir situações em que pessoas foram vítimas de violência sexual. Por vitimado compreende-se as consequências da violência em si, geradas na vítima, a qual tem seus direitos humanos mais elementares violados (vida, educação, saúde, segurança, etc.). Já vitimizado refere-se às consequências geradas após a vítima ser objetalizada (Azevedo \& Guerra, 1989, p. 35), ou seja, a ação abusiva ou omissão de um adulto que gera danos físicos ou psicológicos à criança ou ao adolescente.

A violência sexual trata-se de uma modalidade de violência diretamente relacionada ao gênero. Os dados encontrados na literatura existente revelam que o feminino é o mais vitimado e que as possíveis causas residem nas dimensões androcêntricas e nos aspectos sócio-históricos que nutrem as mais antigas formações sociais (Amazarrey \& Koller, 1998; Antoni \& Koller, 2000; Araújo, 2002; Avancini, 2004; Furniss, 1993; Gabel, 1991; Habigzang \& Caminha, 2004; Habigzang et al., 2005; Libório, 2005; Libório \& Souza, 2004; Mees, 2001; Narvaz, 2005; Pfeiffer \& Salvagni, 2005; Renshaw, 1984).

Apesar de manter alto índice de abuso sexual contra crianças e adolescentes, o Brasil é considerado, no âmbito internacional, um dos países que mais enfrenta a questão, dada a existência de uma legislação que visa proteger a criança e o adolescente. Como forma de proteção, o Governo Federal elaborou, em 2000, o Plano Nacional de Enfrentamento da Violência Sexual Infantil-
Juvenil, homologado pelo Conselho Nacional dos Direitos da Criança e do Adolescente (CONANDA). Em 2001, implantou, no âmbito da Política de Assistência Social, o Programa de Enfrentamento ao Abuso Sexual Infanto-Juvenil, denominado Programa Sentinela, e, no ano seguinte, o programa Ações Integradas e Referenciais de Enfrentamento à Violência Sexual Infanto-Juvenil no Território Brasileiro - PAIR (Avancini, 2004).

$\mathrm{O}$ apoio familiar torna-se fator imprescindível para o encaminhamento da situação de violência vivida pela criança e pelo adolescente. O papel da mãe recebe especial destaque devido ao significado importante na manutenção da sensação de proteção de seu(a) filho(a) (Azevedo \& Guerra, 1989). Tratase de papel determinado a partir dos registros históricos da construção cultural da sociedade em que a mãe ocupa papel de guardiã do equilíbrio familiar. Assim, as vivências subjetivas dela vão ocupar um papel significativo na cena incestuosa, conforme será tratado neste artigo. Todavia, apesar de alguns autores terem versado sobre a questão da família incestogênica - entre eles, Antoni e Koller (2000), Azevedo e Guerra (1993), Furniss (1993) -, este estudo se inscreve abordando a forma como a mãe significa a situação de violência contra a filha. Esse movimento materno é revelador de suas vivências subjetivas na construção de sua subjetividade diante da situação.

Vygotsky (1989) afirma que o sujeito não se constitui de dentro para fora. Tampouco é um reflexo passivo do meio que o circunda, mas, sim, o produto do contexto sociocultural. Os princípios da constituição da consciência e das funções superiores do indivíduo são fundamentados na ideia de que esses processos têm uma "gênese social", provinda das relações do indivíduo com os objetos e com outras pessoas, isto é, das condições objetivas de sua vida social. Esses processos refletem concretamente sua ação sobre os objetos, principalmente, os componentes sociais. Essa "gênese social" significa, em sentido amplo, que toda a cultura é social, pois é produto da vida e da atividade social do indivíduo.

A partir dessa concepção, Bock, Gonçalves, e Furtado (2002) afirmam que a concepção da subjetividade humana implica a compreensão da sua objetividade, na mesma medida em que, para que se conceba o mundo interno, é preciso entender o externo. O sujeito atua sobre o objeto constantemente.

De acordo com Rey (2003), sendo o sujeito definido socialmente a partir das características adquiridas culturalmente, ele entra em contato com diversas outras pessoas que fazem parte do grupo social em que vive e que estão igualmente constituindo-se como sujeito. Esse raciocínio torna inteligível que a composição do sujeito não é algo que existe somente na esfera individual, mas, sim, numa escala coletiva e, portanto, a partir desse sistema subjetivo e objetivo, a subjetividade vai se constituindo. Assim, a construção da subjetividade depende das influências que o indivíduo recebe da sociedade, da cultura, do momento histórico e do seu papel influenciador sobre ela.

É nesse raciocínio sócio-histórico de formação de subjetividade e de vivências subjetivas que se teoriza a condição das mães entrevistadas diante da situação de abuso sexual intrafamiliar contra as suas filhas. Segundo Marcello (2005), à medida que as mães não compreendem a situação da violência em si, não conseguem dispor de mecanismos internos para 
se expressarem abertamente. São mulheres que mantêm uma relação com o mundo que as cerca, com o pensamento voltado para si e seus múltiplos papéis sociais (mãe, esposa e dona de casa), isso porque têm a intenção de atuar da forma mais satisfatória possível.

Marcello (2005) aborda a subjetividade na maternidade como algo relacionado desde o preparo inicial da gravidez. Afirma que a mulher passa a receber orientações da sociedade que a cerca (médicos, familiares, etc.), baseadas na cultura vigente, sobre o compartilhamento factual de seu corpo com o feto. Passa, então, a viver uma situação de responsabilidade a partir da internalização de que o seu corpo não pertence só a si, mas, sim, ao seu filho também, seja como fonte de alimento, seja como subsistência do feto.

De acordo com Badinter (1985), a maternidade é entendida socialmente como um evento altamente feliz na vida da mulher. Um acontecimento que possui em seu entorno somente benefícios. A mãe, contudo, percebe que, diante do mundo em que vive, existem problemas de ordem biológica, psíquica e social que podem ocorrer e, então, afetar a relação com seu(a) filho(a), algo que vai contra a concepção social de que nada abalaria tal relação.

O querer ou não um filho passa pela representação do que se entende por ser mãe. Esse filho tanto pode ser a promessa de continuar a existência da família, como também algo que dará um significado à vida do casal; pode trazer também o risco de rompimento do relacionamento conjugal; pode ser encarado como uma promessa de realização de tudo o que não foi possível ser feito pelos pais; pode ser, inclusive, sinônimo de companhia, de segurança, de que terá alguém para cuidar e que, no futuro, cuidará deles (Maldonado, Bichstein, \& Nahoum, 1996).

Assim, desde a gravidez, a futura mamãe já vai idealizando seu filho, esquecendo-se de admitir a possibilidade de que ele seja alguém totalmente diferente daquilo que ela projetou. Isso pode interferir na relação a ser vivida por pais e filho, pois pode restar pouco lugar para o respeito da individualidade da criança e limitações para a criatividade como pais (Maldonado et al., 1996).

Mas esse amor, afirma Badinter (1985), é conquistado, e não inato, precisando ser exercitado. Discute a natureza instintiva e universal do amor materno, aborda-o como um mito construído pela sociedade (considerando-se também a família isoladamente), que, consequentemente, imagina um ideal de mãe.

De acordo com a perspectiva sócio-histórica, respeitando a trajetória histórica e cultural construída pela família como instituição, o papel da mãe recebe grande importância. Creditase a ela a manutenção do bem-estar físico e emocional de seus filhos, bem como o cuidado com a harmonia da família como um todo (Azevedo \& Guerra, 1993).

De acordo com Badinter (1985), o papel materno idealizado é composto por características aprendidas no seio familiar de origem. Através das gerações, as mulheres se identificam com padrões de comportamento das mulheres de sua família, o que enraíza a noção de responsabilidade pela unidade familiar. Nesses termos, a mulher encontra sua construção identitária e acompanha o modelo cultural em que está mergulhada, o que lhe permite caracterizar-se por um arcabouço cultural próprio.
É essa condição de sujeito, ou seja, a sua subjetividade, que proporciona a essa mulher, mãe, esposa e dona de casa, uma reflexão a respeito de si mesma e de sua relação com os elementos constituintes de sua realidade. Essa reflexão the possibilita efetuar um processo de objetivação de si mesma e de sua modalidade materna, a partir do que consegue visualizar de si e de sua condição de mãe (Marcello, 2005). Segundo este autor, a reflexão acerca de si mesma dará a forma de elaboração da situação adversa em questão. Trata-se da maneira encontrada pela mãe de enfrentar a realidade da violência sexual intrafamiliar, dirigida pelo modo como ela desenvolve e posiciona a sua subjetividade.

Para Azevedo e Guerra (1989), a mãe recebe uma carga de responsabilidade por todos os acontecimentos que ocorrem no seio familiar. Não obstante, a tendência é ser julgada como fraca, negligente, incapaz ou até mesmo conivente com casos de abuso sexual incestuoso. Apesar dos discursos de conivência, culpa e cumplicidade maternas, diante do abuso sexual contra as filhas, a maioria das mães aparenta não estar ciente de que tal abuso ocorre e, quando sabem, conforme mencionado anteriormente, elas são as que mais denunciam os abusos intrafamiliares.

De acordo com teóricos, como Azevedo e Guerra (1993), Faleiros (2000) e Furniss (1993), o valor e a responsabilidade da figura materna crescem principalmente no que se refere ao desdobramento do caso de abuso sexual intrafamiliar do(a) filho(a). Significa que a mãe é quem mais influencia na possível decisão da criança de revelar ou não a violência, e de que forma fazê-lo. É dela também que parte a iniciativa de toda a família no trato com a situação.

Diante disso, o papel materno dessas mães de meninas abusadas sexualmente passa por reformulações oriundas de suas próprias reflexões acerca de seu fazer materno perante os filhos. Após a situação de violência, as mães passam a cuidar mais de seus(as) filhos(as), tornando-se mais protetivas. Ou seja, mães mais atentas e mais próximas a seus(as) filhos(as). Demonstram mais cuidado e preocupação com seus comportamentos diante da sociedade, protegendo-os (Furniss, 1993). Portanto, mediante análise crítica de suas condutas, operam mudanças, passam a buscar uma efetivação de seu papel de mãe, e também de esposa e mulher, mesmo vivendo tal situação adversa.

\section{Método}

Participaram desta pesquisa 13 mães que acompanharam suas filhas, encaminhadas pela Rede de Enfrentamento para atendimento no Programa Sentinela. As meninas foram dirigidas ao Programa devido às suspeitas ou denúncias de abuso sexual intrafamiliar. Tanto mães como filhas foram acompanhadas por meio de atendimento psicossocial no local.

Os procedimentos adotados nesta pesquisa atenderam às determinações da Resolução 196/96 do Conselho Nacional de Saúde, acerca de pesquisas com seres humanos.

Os endereços das usuárias do serviço foram adquiridos no referido Programa Sentinela, no qual a primeira autora já havia trabalhado anteriormente, realizando atendimento psicológico às crianças e aos adolescentes vitimadas e aos seus familiares. Assim, o Programa foi contatado e os objetivos desta 
pesquisa foram explicitados. Tanto se autorizou a efetivação das entrevistas, quanto o Programa facilitou o contato com as mães participantes deste estudo. Neste contato, expuseram-se os objetivos da pesquisa para a qual as mães foram convidadas a participar, e esclareceram-se os procedimentos a serem efetivados - dispostos no Termo de Consentimento Livre e Esclarecido assinado pelas participantes.

Para seleção da amostra, utilizou-se o critério de saturação (Sá, 1998), no qual o número de sujeitos foi indicado a partir da repetição das informações dos relatos das entrevistadas, o que possibilitou a contemplação dos objetivos traçados nesta pesquisa.

Quanto ao instrumento, utilizou-se uma entrevista semiestruturada, composta por duas partes. A primeira parte versava sobre dados biossociodemográficos das entrevistadas; $\mathrm{e}$ a segunda, sobre as experiências com a violência de suas filhas, os procedimentos adotados a partir do conhecimento da situação de abuso intrafamiliar, e suas vivências subjetivas. $\mathrm{O}$ roteiro e a forma dada à segunda parte do instrumento foram inspirados na história de vida tópica (Minayo, 1994), a partir da qual se enfatizou e explorou uma determinada situação ou etapa da vida do entrevistado, neste caso, a situação do abuso sexual de filhas das mães pesquisadas.

Para o tratamento dos dados, utilizou-se a técnica de análise de conteúdo temático de Bardin (2007), enfatizando-se a ausência ou a presença do tema, a despeito de sua frequência. Procedeuse à transcrição integral das entrevistas; em seguida, fez-se a leitura flutuante, a fim de conhecer o conteúdo e, então, captar as primeiras impressões e orientações a partir de sua análise. Os dados foram tabulados para se fazer o recorte das unidades temáticas; codificados, com a finalidade de agrupar o recorte das unidades temáticas e construir as categorias; e categorizados, com o objetivo de elaborar uma representação simplificada do conteúdo. Por fim, realizou-se inferência e interpretação dos dados, com o intuito de descrevê-los e estabelecer relações com os fundamentos teóricos adotados.

\section{Resultados}

\section{O perfil biossociodemográfico}

As mães entrevistadas tinham, na época da pesquisa, idades que variavam de 25 a 50 anos, sobressaindo-se 8 na faixa etária de 30. Das 13 mães que participaram da pesquisa, 4 definiramse como não trabalhadoras ou "do lar" e 9 definiram-se como trabalhadoras nas atividades de copeira, lavadeira de roupas, manicure, funcionária pública, diarista, empregada doméstica e técnica em Enfermagem. No que concerne ao grau de escolaridade das entrevistadas, verificou-se que oito têm ensino fundamental e cinco, ensino médio completo (uma delas cursou o ensino técnico).

Entre as participantes da pesquisa, nove revelaram que mantinham relações maritais antes do conhecimento do abuso sexual contra suas filhas e quatro, não. Entre as que conservavam, três romperam após o abuso sexual intrafamiliar de sua filha, sendo, nesses casos, seus companheiros os abusadores. Ao falarem de seus relacionamentos maritais, as entrevistadas revelaram história de vários maridos, que, segundo elas, poderiam chegar a três companheiros.

O número de filhos que as entrevistadas possuíam na época da pesquisa variava entre três e sete - apenas uma entrevistada tinha uma filha. Uma das características revelada e comum à maioria das entrevistadas é a geração de filhos na maior parte dos relacionamentos.

As 13 entrevistadas revelaram que os abusadores de suas filhas, em 5 das situações, eram seus companheiros (sendo que 3 eram genitores e 2 eram padrastos das meninas); em 6, o agressor era seu cunhado, 1 era seu compadre e 1 era seu filho.

Essas mulheres ocupavam, à época da pesquisa, o lugar de principal provedora da renda familiar, com renda média mensal de $\mathrm{R} \$ 100,00$ a R \$620,00. As casas das participantes se localizavam em bairros periféricos, ou seja, um trecho urbano com infraestrutura precária - tanto no que se refere ao saneamento básico como ao acesso a equipamentos institucionais, como creches, escolas e serviços de saúde.

Entre as participantes da pesquisa, cinco residiam com parentes (mãe, irmãos, cunhados, sobrinhos, etc.). Quando não habitavam a mesma residência, tinham sua casa construída no terreno contíguo ao de outro familiar.

\section{Vivências subjetivas}

Essa categoria trata do modo como as mães experimentaram o sofrimento ao se depararem com o ocorrido às suas filhas. Diante disso, a análise dos relatos das mães entrevistadas permitiu a composição de dois blocos de subcategorias: afetiva e cognitiva. Tal divisão entre as subcategorias deu-se somente para fins didáticos.

$\mathrm{Na}$ subcategoria afetiva estão dados relacionados ao sentimento que as participantes experienciaram diante do abuso sexual praticado contra as filhas, a exemplo de sofrimento subjetivo expresso como culpa, desamparo denotando um embotamento afetivo, e revivência do próprio abuso sexual. São falas que revelam o momento em que essas mães associam a situação que estão vivendo com a filha de forma direta com a sua também vitimação sexual no passado. Dessa forma, os achados desta pesquisa revelaram que, dentre as 13 mães participantes, 4 também foram vitimadas por abuso sexual quando eram crianças ou adolescentes.

\footnotetext{
Eu também quando... quando criança, eu fui abusada tanto pelos irmãos como pelo tio, como por primo ... Então eu sabia o que minha filha tinha passado... Aí, foi isso. Eu não converso com ele até hoje. (...) É... eu me senti... é porque assim... geralmente as pessoas não acredita. Que ninguém acreditou em mim, cê tá entendendo?... Então, eu procurei acreditar na minha filha. (...) Não é falta, assim, de carinho, não é falta de compreensão, não é falta de diálogo, cê tá entendendo? É que eu já tenho aquilo dentro de mim. Há muito tempo que eu acho que ninguém me ouviu. Ninguém não, não foi trabalhado isso comigo, cê tá entendendo? Quando você fala: “Ê, sua sem vergonha!” Pei; descia a porrada em você. E ninguém acreditava, cê tá entendendo? Você tinha que se esconder sozinha... (Sra. D., 38 anos, cuja filha foi vitimada pelo seu cunhado)
}

$\mathrm{Na}$ subcategoria cognitiva estão dados reveladores da 
forma como as entrevistadas entraram em contato ou tomaram conhecimento do abuso sexual praticado contra sua filha. Essa subcategoria foi classificada em conhecimento - constituída por falas das mães que versaram sobre histórias de abuso de outras pessoas que não sua filha e do modo como tomaram conhecimento do abuso sexual sofrido pelas filhas - e desconhecimento - quando as mães referiram situações em que tiveram a desconfiança de que algo pudesse ter acontecido, além de dados que revelam a completa surpresa das mães quando se depararam com a situação de abuso das filhas.

\section{Procedimentos adotados pelas mães}

Este estudo apontou que as mães entrevistadas, ao tomarem conhecimento do abuso sexual sofrido por suas filhas, procediam por sua própria iniciativa ou por orientação de terceiros. No caso de iniciativa própria, procuraram saber com as filhas o que havia acontecido, tentaram fazer justiça com as próprias mãos, agredindo o abusador ou denunciando-o.

Sentei com ela na cama e falei: "S - nós tinha tido uma briga, tava até machucada: o X tocou em você... alguma vez? Ele por acaso apareceu aqui?". Ela: "Não mãe". Eu digo: "Você nunca teve nada com ele minha filha?". Ela disse: "Não mãe.”. Eu disse: "Filha, por favor!". Aí, eu fui... fui meia ridícula mas eu precisei fazer isso, digo: "Olha $\mathrm{S}$ tô toda machucada, a gente teve uma discussão, eu não sei por que ele tá assim. Você já ficou com ele?”. Ela falou pra mim: “Ah, já, uma vez”. Aí, eu desmontei, né? (Sra. C., 34 anos. O abusador de sua filha foi o seu ex-marido, padrasto da menina)

Quanto ao procedimento adotado pela mãe a partir da orientação de outras pessoas, os dados revelaram que, entre as pessoas que orientaram essas mães quando tomaram conhecimento da violência, estão seu próprio pai, sua amiga, seu vizinho ou um policial, conforme relato a seguir:

Aí, ela ficou doida né? "Vamo dar parte! Vamo dar parte!". Foi quando ela levou a gente lá pro postinho ali. Aí, chegou no postinho. Aí, o médico falou: "Não, tem que ser no, tem que ser no ML, né? No ML lá, lá em...” Aí, ela pegou deu parte, né? Chamou, chamou a polícia. Ela levou a polícia lá, mas ele já tinha ido embora. Ele já tinha se entregado. Já tava lá na Central quando nós chegamo lá. Ele já tava lá dizendo que nós tava levantando falso testemunho, né e tal... (Sra. Z, 50 anos, cuja filha foi violentada pelo padrinho)

O conjunto das atitudes tomadas indica que, quando a mãe se revela bastante próxima a suas filhas (acompanhando mais de perto suas atividades, permanecendo mais tempo com elas), a mãe consegue reconhecer sinais de mudança no processo familiar (comportamento do marido, dos filhos, etc.). Dessa forma, segundo as entrevistadas, pelo fato de considerarem-se protetoras (afirmando-se mais cuidadosas e carinhosas com os filhos em geral), têm a postura de interromper a continuidade da violência assim que captam os sinais da incidência.

A proximidade com os filhos proporcionava às mães a possibilidade de perceber mudanças no comportamento deles, o que as auxiliava, segundo relato das entrevistadas, na captação de indícios de que algo estranho, a exemplo do abuso, poderia estar acontecendo.

\section{Implicação para as mães após o abuso sexual de sua filha}

Essa categoria refere-se às consequências sofridas pelas mães com a vivência da situação do abuso intrafamiliar. Trata-se de mudanças geradas na forma de se colocar diante da vida. Os dados revelam que, após terem conhecimento do abuso de suas filhas, embora tomem atitudes para defender todos os filhos, ficam, como mulheres, abaladas com o ocorrido. Os dados revelaram que as participantes da pesquisa experimentaram sentimentos variados, como negação da violência, não saber em quem confiar, medo e vulnerabilidade, e a crença em respostas mágicas.

A negação da violência decorre, principalmente, da quebra da confiança depositada no agressor, do sentimento afetivo dirigido a ele e da relação desgastada com a filha. Não saber em quem confiar decorre da confusão vivenciada pela mãe que fica dividida entre crer no agressor ou na filha, aspecto que se torna mais grave quando o agressor é o companheiro da mãe. O medo e a vulnerabilidade apareceram também expressando a sensação de suscetibilidade das participantes da pesquisa diante do agressor, de outros homens e, muitas vezes, do meio em geral (não sair de casa nem deixar os filhos saírem). As respostas mágicas referem-se às menções que essas mães fazem a figuras divinas, associando a estas os meios para sair da sensação de desconforto que vivenciam. Atribuíram a Deus, como guia de seus comportamentos, uma responsabilidade sobre algumas atitudes:

Nós íamos casar. Marcamos até data de casamento. E eu fui aos pés do Senhor. Me ajoelhei e falei: "Deus, eu não tô sentindo paz nesse negócio. Me ajude mesmo!’ E Deus me deu a palavra de que não era pra ser. Então eu... desisti de casar. Dias já. Com vestido pronto e tudo. Tudo mesmo. Faltava cinco dias... (Sra. C, 34 anos, cuja filha foi vitimada pelo seu ex-companheiro, padrasto da menina)

\section{Discussão}

No caso desta pesquisa, o abuso sexual intrafamiliar envolveu mães na faixa etária entre 25 e 50 anos, economicamente pobres, em sua maioria, trabalhadoras e únicas provedoras da renda da família, que cuidam sozinhas dos filhos oriundos de vários relacionamentos, e que também foram, assim como suas filhas, abusadas sexualmente na infância ou adolescência.

Existe uma controvérsia a respeito da relação entre condições econômicas e incidência de abuso sexual intrafamiliar. Habigzang e Caminha (2004) e Leal e Cesar (1998) relacionam a violência sexual intrafamiliar às condições econômicas das famílias, afirmando ser de maior incidência em famílias com baixas condições econômicas. Acrescentam que a forma com que a realidade da pobreza interfere nas incidências de abuso sexual infanto-juvenil intrafamiliar se configura no modo de se lidar com o fato e em suas implicações na vida da família. No entanto, Habigzang e Caminha (2004) atentam para que não se generalize, afirmando não ser uma regra que a pobreza estará 
sempre ligada ao abuso sexual infanto-juvenil, explicando que nem sempre uma família pobre comete práticas abusivas.

Pfeiffer e Salvagni (2005) traçaram um perfil de como as famílias de diferentes condições econômicas tratam a situação da violência internamente. Famílias de classe média costumam esconder o fato para não serem expostas à sociedade a partir do problema; não costumam revelar a sua condição de desequilíbrio. Já as mais pobres costumam revelar mais, impondo também responsabilidade aos órgãos competentes na solução do problema.

Mais que os aspectos socioeconômicos, há que se destacar a vivência dessa mulher, mãe que se sente só e desprotegida. Sua vivência envolveu um sofrimento subjetivo, expresso na culpa, que reacendeu as lembranças de seu próprio abuso. Segundo Araújo (2002) e Furniss (1993), um dos sentimentos iniciais vivenciados pelas mães nos casos de abuso sexual intrafamiliar é uma confusão diante da suspeita ou constatação de que o companheiro abusa sexualmente do(a) filho(a) e também frente aos sentimentos ambivalentes desenvolvidos em relação ao vitimado. Ao mesmo tempo em que sente raiva e ciúme, atribui a si a culpa por não protegê-lo. Na verdade, a mãe é igualmente vítima da violência intrafamiliar. Negar, desmentir o filho vitimado ou culpá-lo pela sedução é uma forma de suportar o impacto da violência, desilusão e frustração diante da ameaça de desmoronamento da família.

As mães também sentem dificuldade em expressar afetos, emoções (quer de tristeza, quer de raiva, quer de alegria, etc.), sensação de distanciamento e falta de perspectivas. Trata-se de sentimentos experimentados por elas desde o momento em que tomaram conhecimento do abuso sexual praticado contra seus(as) filhos(as) e que perpassam todo o processo de elaboração acerca do problema. Tal característica é responsável pela sensação de inadequação ao mundo ao seu redor (Furniss, 1993; Habigzang \& Caminha, 2004). Vivenciam sentimento de culpa ao se darem conta de que não conseguem exercer o papel materno inicial de proteção de seus(as) filhos(as) da violência sofrida. É um sentimento voltado para a sensação de ausência, no que tange ao acompanhamento dos(as) filhos(as), como também relacionado a suas dificuldades em lidar com a situação de violência que as obriga a recordar sua própria vitimação no passado (Araújo, 2002; Freitas, 2002; Furniss, 1993; Narvaz, 2005).

A sensação de ausência vivenciada pelas mães nessa situação de violência relaciona-se, ainda, ao fato de elas não se fazerem literalmente presentes nos momentos em que os abusos acontecem. Habigzang e Caminha (2004) apontam a existência de vários casos em que a mãe e o pai (ou padrasto) possuem horários de trabalho diferentes, o que propicia a situação de essa figura masculina estar sozinha com o(a) filho(a) em casa.

A literatura associa o sentimento de desamparo ao que as mães vivenciam como culpa. Entre os motivos pelos quais as mães se sentem desamparadas estão a distância da família e a carência de acolhimento profissional (Freitas, 2002; Furniss, 1993; Habigzang \& Caminha, 2004). As mães apresentam dificuldade em perceber o que ocorre com suas filhas, quer por medo ou desproteção, quer por dor, confusão e ambivalência diante da nova situação de abuso. Acrescenta-se a isto as mães, geralmente, não receberem suporte de suas próprias mães, mostrando-se, na vida adulta, dependentes, emocional ou economicamente, dos companheiros, que, geralmente, são os agressores (Narvaz, 2005).

Assim, já conheciam o abuso sexual por si mesmas e também por terem ouvido falar. No entanto, desconheciam os de suas filhas. De acordo com Furniss (1993), em casos em que as mães não percebem a ocorrência do abuso sexual intrafamiliar contra suas filhas, as próprias vitimadas o relatam com o intuito de cessar as vitimações. Isto ocorre mesmo diante da iminência de uma possível punição advinda das mães, que podem não acreditar no relato, como também dos abusadores, que podem cumprir ameaças. Outra forma encontrada pelas vitimadas para revelar o abuso a suas mães é o envolvimento de pessoas de seu círculo pessoal, em quem ela deposita certo grau de confiança, como parentes, professores, colegas, etc.

A discussão acerca do conhecimento ou não, pela mãe, sobre a violência praticada contra sua filha no âmbito domiciliar é tema de diferentes opiniões na literatura existente sobre o assunto. Segundo Narvaz (2005), muitas mães, de fato, desconhecem a realidade do abuso sexual. São mulheres que, muitas vezes, possuem uma história passada de vitimização semelhante e que, dessa forma, encontram barreiras emocionais para admitirem a incidência na sua família.

Em contrapartida, Saffioti (1999) afirma que as mães sempre sabem da ocorrência do abuso sexual intrafamiliar contra suas filhas. No entanto, esse conhecimento é algo que ocorre em nível inconsciente, ou seja, embora desconfiem (o que a autora considera como intuição), não creem, pois não possuem provas do ocorrido.

Histórias de abuso sexual que dizem respeito a outros parentes, e de que as mães tomam conhecimento, não abalam a crença de que poderia acontecer um dia na vida delas, dentro de sua família. Esse dado é apresentado na literatura pesquisada como reação inicial gerada nas mães que tendem a negar e desmentir a possibilidade de incidência do abuso sexual intrafamiliar (Furniss, 1993; Narvaz, 2005).

Assim, as vivências subjetivas das mães diante da situação estudada é tema de profundas discussões. Contudo, este artigo mostra que elas sofrem com tal situação e chegam a questionarem-se acerca de seu papel como mães, o que as torna recorrentes vítimas da realidade vivida por elas.

Ao tomarem conhecimento, as mães agem por si ou por iniciativa de terceiros. Quando próximas às suas filhas, tomam a iniciativa de interromper a continuidade da violência assim que captam os sinais da incidência. As mães que procediam por iniciativa própria o faziam diante da percepção de mudanças no comportamento das filhas, dos maridos ou companheiros, o que indicava maior proximidade aos filhos. Assumiam, então, a postura de interromper a continuidade da violência assim que captavam os sinais da incidência. Esses dados corroboram achados de outros autores (Azevedo \& Guerra, 1993; Badinter, 1985; Felipe, 1999; Furniss, 1993; Narvaz, 2005) que afirmam que, geralmente, são as mães que revelam o abuso, tomando medidas para proteger os filhos.

Esta pesquisa demonstrou, ainda, que as ações efetivadas pelas mães, seja por iniciativa própria ou por orientação de outras pessoas, estão baseadas na intenção de organizar a família 
em busca de solução para o conflito, partindo da proteção das filhas vitimadas. Esse aspecto corrobora estudo de Habigzang et al. (2005) que identificou que, entre as estratégias de proteção de sua filha, acionadas pelas mães, está, em primeiro lugar, o afastamento da vítima (abrigamento com 50\%); seguida de abandono do companheiro agressor, por obra da mãe (35\%); prisão do agressor ou seu afastamento do lar (31\%); e proteção do vitimador, por parte dos familiares ou da menina vitimada (14\%).

Tanto a literatura pesquisada como os achados desta pesquisa revelam que a mãe é peça importante no desenvolvimento interno da família, o que gera preocupação acerca de sua autoavaliação como tal, isto é, se está sendo boa ou não. Nesse momento, esbarra na cobrança social de ser amorosa com seus(as) filhos(as) de forma incondicional, o que, muitas vezes, não é a sua realidade, por se sentir insegura com a situação e o mundo em geral.

Diante de tais vivências, há repercussões em suas vidas: negação da violência, não saber em quem confiar, medo e vulnerabilidade, e crença em respostas mágicas. Esses dados corroboram a literatura pesquisada, que revelam que, quando as mães tomam conhecimento da violência praticada pelo agressorsendo este alguém de seu convívio familiar-, elas podem iniciar um processo de negação da violência, por não crerem em sua filha (Furniss, 1993).

A literatura demonstra que, entre mães que sofreram essa experiência, há um sentimento de distanciamento com o mundo, bem como perda de interesse em estabelecer relações sociais, principalmente, as novas. Também indica muita dificuldade das mães em conectarem-se com emoções, especialmente, as associadas à intimidade e sexualidade; além da incapacidade para recordar o trauma. Trata-se de sintomas que tendem a se acentuar, na medida em que o indivíduo se encontra em situações que recordem ou simbolizem o trauma original (Freitas, 2002; Furniss, 1993; Habigzang \& Caminha, 2004).

\section{Conclusão}

A vivência dessas mães diante do abuso sexual intrafamiliar praticado contra suas filhas envolveu um sofrimento subjetivo, expresso na culpa, que reacendeu as lembranças de seu próprio abuso. Elas associaram sua experiência de abuso no passado diretamente com a situação das filhas. No entanto, revelaram que sua forma de conduta, diante do abuso sexual contra a filha, algumas vezes, baseou-se nas atitudes de suas mães na época de sua vitimação.

Diante de tais vivências, há repercussões em suas vidas, carregadas de experiências negativas. Tratam-se do modo como conseguem elaborar a situação, diante das implicações geradas em suas vidas, como também das construções subjetivas de ordem afetiva e cognitiva.

As mães revelaram as mudanças existentes em seu comportamento ao tomarem conhecimento do abuso sexual praticado contra sua filha. Adquiriram comportamentos que antes não tinham, como, por exemplo, ficar mais desconfiadas do mundo ao seu redor. Expressaram sentimentos de vulnerabilidade traduzidos em relatos de desamparo - voltados à falta de apoio da própria família, como também dirigida aos sistemas de garantias de direitos -, culpa e desconfiança. Portanto, suas vivências subjetivas são os principais pilares para o seu comportamento diante do abuso sexual intrafamiliar praticado contra sua filha.

É a partir de sua constituição como sujeito que essa mãe vai reagir diante da situação. Em outras palavras, o seu comportamento será apoiado em sua construção sócio-histórica, ou seja, nas concepções estabelecidas, durante sua vida, acerca do fazer materno, no seu modo geral, bem como diante de uma situação adversa, como é o caso do abuso sexual intrafamiliar com que se depara.

As vivências subjetivas das mães entrevistadas diante do abuso sexual intrafamiliar de suas filhas são determinantes para a forma de condução de toda a família frente à situação vivida. Assim, o sofrimento gerado com a experiência é capaz de dificultar toda a efetivação das ações diante do problema familiar. Essa elaboração articula-se diretamente com o tipo de acolhimento, atendimento e acompanhamento que a mãe recebeu - o que auxilia em sua elaboração acerca da situação vivida, assim como ajuda os outros membros da família a fazê-lo.

Em situações de violência sexual, a importância do desenvolvimento de políticas públicas se torna urgente para todos os sujeitos envolvidos, não somente dirigida à própria criança $\mathrm{e}$ ao adolescente vitimados, mas também a toda a sua família, em especial à mãe. Isso porque, entre as implicações para a família existentes nesse entorno está a reprodução transgeracional dessa violência. $\mathrm{O}$ fato de essa mãe receber ou não apoio altera a sua forma de lidar com a situação, pois ela pode posicionar-se como defensora ou negligente. As mães, como referenciais familiares de desenvolvimento de ações, tornam-se peças-chave que precisam de atenção e acolhimento adequados para restauraremse subjetivamente.

\section{Referências}

Aded, N. L. O., Dalcin, B. L. G. S., Moraes, T. M., \& Cavalcanti, M. T. (2006) Abuso sexual em crianças e adolescentes: revisão de 100 anos de literatura. Revista de Psiquiatria Clínica, 33(4), 204-213.

Amazarrey, M. R., \& Koller, S. H. (1998). Alguns aspectos observados no desenvolvimento de crianças vítimas de abuso sexual. Psicologia: Reflexão e Crítica, 11(3), 559-578.

Antoni, C., \& Koller, S. H. (2000). A visão de família entre as adolescentes que sofreram violência intrafamiliar. Estudos de Psicologia (Natal), 5(2), 347-381.

Araújo, M. F. (2002). Violência e abuso sexual na família. Psicologia em Estudo, $7(2), 3-11$.

Ariès, P. (1981). História social da criança e da família (2ª ed.). Rio de Janeiro: Guanabara.

Avancini, E. V. (2004). Caracterização das crianças e adolescentes usuários do Programa Sentinela, de Medianeira - PR. Revista Virtual de Textos \& Contextos, 3(3), 1-15. Recuperado de http://revistaseletronicas.pucrs/ojs/ index.php/fass/article/viewfile/987/767

Azambuja, M. R. F. (2004). Violência sexual intrafamiliar: é possível proteger a criança? Porto Alegre: Livraria do Advogado.

Azevedo, M. A., \& Guerra, V. N. A. (1989). Crianças vitimizadas: a síndrome do pequeno poder. São Paulo: Iglu.

Azevedo, M. A., \& Guerra, V. N. A. (Orgs.). (1993). Infância e violência doméstica: fronteiras do conhecimento. São Paulo: Cortez.

Badinter, E. (1985). Um amor conquistado: o mito do amor materno (10ª ed., W. Dutra, Trad.). Rio de Janeiro: Nova Fronteira. 
Bardin, L. (2007). Análise de conteúdo. Lisboa: Edições 70.

Bock, A. M. B., Gonçalves, M. G. M., \& Furtado, O. (Orgs.). (2002). Psicologia sócio-histórica: uma perspectiva crítica em psicologia (2 $2^{-}$ed.). São Paulo: Cortez.

Centro de Referência, Estudos e Ações sobre Crianças e Adolescentes. (s/d). Disque denúncia nacional de abuso e exploração sexual contra crianças e adolescentes - 100. Recuperado de http://www.cecria.org.br/ banco/Dados\%20gerais\%20-\%20Rel\%20at\%C3\%A9 \%20novembro. doc? articleid $=980 \&$ zoneid $=19$

Cohen, C. (1993). O incesto um desejo. São Paulo: Casa do Psicólogo.

Faleiros, E. T. S. (2000). Repensando os conceitos de violência, abuso e exploração sexual de crianças e de adolescentes. Brasília: Thesaurus.

Felipe, S. (1999). Violência sexual na família e cumplicidade institucional. Texto \& Contexto, 8(2), 77-100.

Forward, S., \& Buck, C. (1989). A traição da inocência: o incesto e sua devastação. Rio de Janeiro: Rocco.

Freitas, R. C. S. (2002). Famílias e violência: reflexões sobre as mães de Acari. Psicologia USP, 13(2), 69-103.

Furniss, T. (1993). Abuso sexual da criança: uma abordagem multidisciplinar. Porto Alegre: Artes Médicas.

Gabel, M. (Org.). (1991). Crianças vítimas de abuso sexual. São Paulo: Summus.

Habigzang, L. F., \& Caminha, R. M. (2004). Abuso Sexual contra crianças e adolescentes: conceituação e intervenção clínica. São Paulo: Casa do Psicólogo.

Habigzang, L. F., Koller. S. H., Azevedo, G. A., \& Machado P. X. (2005). Abuso sexual infantil e dinâmica familiar: aspectos observados em processos jurídicos. Psicologia: Teoria e Pesquisa, 21(3), 341-348.

Leal, M. F. P., \& César, M. A. (Org.). (1998). Indicadores de violência intrafamiliar e exploração comercial de crianças e adolescentes: relatório final. Brasília: Ministério da Justiça.

Libório, R. M. C., \& Souza, S. M. G. (Orgs.). (2004). A exploração sexual de crianças e adolescentes no Brasil: reflexões teóricas, relatos de pesquisas e intervenções psicossociais. São Paulo: Casa do Psicólogo.

Libório, R. M. C. (2005). Adolescentes em situação de prostituição: uma análise sobre a exploração comercial na sociedade contemporânea. Psicologia: Reflexão e Crítica, 18(3), 413-420.

Maldonado, M. T., Bichstein, J., \& Nahoum, J. C. (1996). Nós estamos grávidos ( $8^{\mathrm{a}}$ ed.). São Paulo: Saraiva.

Marcello, F. A. (2005). Enunciar-se, organizar-se, controlar-se: modos de subjetivação feminina no dispositivo da maternidade. Revista Brasileira de Educação, s/v(29), 139-151.

Mees, L. A. (2001). Abuso sexual, trauma infantil e fantasias femininas. Porto Alegre: Artes e Ofícios.

Minayo, M. C. S. (1994). O desafio do conhecimento: pesquisa qualitativa em saúde (3a ed.). São Paulo/Rio de Janeiro: Hucitec/Abrasco.

Narvaz, M. G. (2005). Submissão e resistência: explodindo o discurso patriarcal da dominação feminina. Porto Alegre: UFGRS.

Pfeiffer, L., \& Salvagni, E. P. (2005). Visão atual do abuso sexual na infância e adolescência. Jornal de Pediatria, 81(5), 197-204.

Renshaw, D. C. (1984). Incesto: compreensão e tratamento. São Paulo: Roca.

Rey, F. G. (2003). Sujeito e subjetividade: uma aproximação histórico-cultural. São Paulo: Pioneira.

Sá, G. P. (1998). A construção do objeto de pesquisa em representações sociais. Rio de Janeiro: UERJ.

Saffioti, H.(1999). Filhas de pais sexualmente abusivos. In H. B. Hollanda \& M. H. Capelato (Orgs.), Relações de gênero e diversidades nas Américas (pp. 113-143). São Paulo: EDUSP.

Secretaria Especial dos Direitos Humanos \& Ministério da Educação. (2004). Guia escolar: métodos para identificação de sinais de abuso e exploração sexual de crianças e adolescentes. Brasília: Autor.

Vygotsky, L. S. (1989). Pensamento e linguagem (2⿳亠口了 ed.). São Paulo: Martins Fontes.

1. Este artigo apresenta parte dos dados obtidos em dissertação realizada pela primeira autora que teve como objetivo compreender as vivências subjetivas das mães que tiveram filhas abusadas sexualmente no contexto familiar.

Joana Azevêdo Lima, mestre em Psicologia Social pela Universidade Federal da Paraíba (UFPB), é doutoranda na mesma instituição e pesquisadora do Núcleo de Pesquisa e Estudos sobre o Desenvolvimento da Infância e Adolescência (NUPEDIA/UFPB). Endereço para correspondência: Rua Juarez Távora, 3000, ap. 404, Edifício Medade, Bairro Torre, João Pessoa-PB, 58.040-022. Telefone: (83) 9928-9555. E-mail: joazeli@hotmail.com Maria de Fatima Pereira Alberto, doutora em Sociologia pela Universidade Federal de Pernambuco (UFPE), é Professora Adjunta do Departamento de Psicologia e do Programa de Pós-graduação em Psicologia Social da Universidade Federal da Paraíba (UFPB) 